\title{
Association between the angiotensin converting enzyme gene insertion/deletion polymorphism and metabolic disturbances in women with polycystic ovary syndrome
}

\author{
KATARZYNA OŻEGOWSKA ${ }^{1}$, ANNA BOGACZ ${ }^{2,3}$, JOANNA BARTKOWIAK-WIECZOREK ${ }^{2,3}$, \\ AGNIESZKA SEREMAK-MROZIKIEWICZ ${ }^{4}$ and LESZEK PAWELCZYK ${ }^{1}$
}

\begin{abstract}
${ }^{1}$ Department of Infertility and Reproductive Endocrinology, Poznań University of Medical Sciences, 60-535 Poznań
${ }^{2}$ Department of Pharmacology and Phytochemistry, Institute of Natural Fibers and Medicinal Plants, 61-707 Poznań;

${ }^{3}$ Laboratory of Experimental Pharmacogenetics, Department of Clinical Pharmacy and Biopharmacy, Poznań University of Medical Sciences, 61-861 Poznań; ${ }^{4}$ Laboratory of Molecular Biology, Division of Perinatology and Women's Diseases, Poznań University of Medical Sciences, 60-535 Poznań, Poland
\end{abstract}

Received February 29, 2016; Accepted June 29, 2016

DOI: $10.3892 / \mathrm{mmr} .2016 .5910$

\begin{abstract}
Polycystic ovary syndrome (PCOS) is a common endocrine disorder in women of reproductive age. A number of PCOS complications may be associated with the elevated level of angiotensin II and low bradykinin concentrations. The aim of the present study was to investigate the frequencies of angiotensin converting enzyme (ACE) gene insertion/deletion (I/D) polymorphisms in women with PCOS and to determine the association between ACE genetic variants and the risk of metabolic and cardiovascular complications in such women. A total of 138 PCOS patients and 110 healthy volunteers were enrolled. Cardiovascular risk was estimated according to the criteria of the American Heart Association and Androgen Excess and PCOS Society. The median average age was 28.5 (26.0-31.0) and 27.0 (24.0-30.0) years in the control and PCOS groups, respectively $(\mathrm{P}=0.004)$. Anthropometric parameters, including body mass index and waist circumference were significantly higher in the PCOS patients. In the PCOS group, 97 (57.4\%) of the subjects were metabolically unhealthy, whereas, in the control group 51 (46.4\%) subjects were $(\mathrm{P}=0.07)$. The II, ID, and DD genotypes frequencies
\end{abstract}

Correspondence to: Dr Katarzyna Ożegowska, Department of Infertility and Reproductive Endocrinology, Poznań University of Medical Sciences, Polna 33, 60-535 Poznań, Poland

E-mail:k.ozegowska@gmail.com

Abbreviations: ACE, angiotensin converting enzyme; CVD, cardiovascular disease; HC, hip circumference; I/D, insertion/deletion; $\mathrm{MH}$, metabolically healthy; MU, metabolically unhealthy; OGTT, oral glucose tolerance test; PCOS, polycystic ovary syndrome; RAS, renin-angiotensin system; WC, waist circumference; WHR, waist to hip ratio; VAI, visceral adipose index

Key words: polycystic ovary syndrome, metabolic syndrome, ACE I/D gene polymorphism, insulin resistance were $29.1,44.5$, and $26.4 \%$ in the controls and 5.0, 37.7, and $57.3 \%$ in the PCOS patients. The cardioprotective I allele was observed significantly less frequently in the women with PCOS compared with the controls [odds ratio (OR), 3.27; $\mathrm{P}=0.0001$ ]. The DD genotype, which is known to increase cardiovascular risk, was more frequently observed in PCOS patients (OR, 3.87; $\mathrm{P}=0.0003$ ), whereas the cardioprotective II genotype occurred in this group less frequently $(\mathrm{OR}, 0.4 ; \mathrm{P}=0.06)$. The results of the present study demonstrated a statistically significant association between the ACE I/D polymorphism and the presence and intensity of metabolic disturbances in women with PCOS.

\section{Introduction}

The renin-angiotensin system (RAS) is known to be a regulator of blood pressure and fluid balance in organisms, however, evidence suggests that it may also be important in the regulation of follicular development, oocyte maturation, ovulation, and steroidogenesis, in addition to the formation of the corpus luteum (1). Angiotensin converting enzyme (ACE), one of the most important components of RAS, is a zinc metallopeptidase involved in the conversion of angiotensin I to angiotensin II, and in the degradation of bradykinin (2). It is expressed in multiple tissues, including the ovaries (2), and exists in a membrane-anchored form on the surface of endothelial and epithelial cells and as a circulating plasma form (3). Ovarian tissues contain prorenin/renin, angiotensinogen, and ACE essential for the production of angiotensin $(2,4,5)$. In vitro studies have demonstrated that ACE is responsible for the angiogenesis of ovarian endothelium (6), steroidogenesis (7), resumption of meiosis (8), and follicular growth (9).

Polycystic ovary syndrome (PCOS) is a common endocrine disorder present in 5-10\% of women of reproductive age, consisting of anovulation, hyperandrogenism, insulin resistance $(10,11)$, and long-term metabolic and cardiovascular complications (12). Previous studies have evaluated environmental and genetic factors that may contribute to the etiology 
of PCOS $(11,13)$. Although $>70$ candidate genes have been investigated for a role in the development of PCOS and its complications, the results have been inconclusive, indicating that abnormalities in other genes may be key factors in the pathogenesis of PCOS (14-16). Few studies have described the role of ACE in human ovaries and the etiology of PCOS. It appears that certain complications of PCOS may be associated with elevated levels of angiotensin II and low bradykinin concentrations $(1,17)$. Individual variations in plasma ACE concentration are associated with the insertion (I)/deletion (D) polymorphism in the 287 bp DNA sequence situated in intron 16 of the ACE gene (18). Previous studies have indicated that receptors for angiotensin II are present on steroidogenic cells responsible for the synthesis of steroid hormones $(1,2,4)$. It has also been demonstrated that the ovarian RAS in women with PCOS may be upregulated (4) and, particularly, the presence of the D allele results in higher levels of plasma ACE (18), which subsequently leads to elevation of angiotensin II levels and disorder of steroid hormone synthesis (19). Recent studies have investigated the importance of the ACE gene $\mathrm{I} / \mathrm{D}$ polymorphism in PCOS, insulin resistance, and hyperandrogenism $(20,21)$, however, they have returned contradictory findings.

The aim of the present study was to analyze the frequencies of the ACE gene I/D polymorphisms in a group of women with PCOS compared with a control group consisting of healthy women, and to determine the association between the ACE genetic variants and the risk of metabolic and cardiovascular complications in women with PCOS.

\section{Materials and methods}

Study subjects. Patients were recruited from the Department of Infertility and Reproductive Medicine of Poznań University of Medical Sciences between July 2012 and December 2013. A total of 138 patients were included in the study group. The diagnosis of PCOS was confirmed according to the Rotterdam consensus criteria (22). Other endocrinopathies and associated disorders were excluded by measuring basal prolactin, thyroid stimulating hormone and 17-hydroxyprogesterone levels. Hyperandrogenism was identified based on the presence of hirsutism as demonstrated by a Ferriman-Gallwey score (FG) (23) of $>8$ and/or presence of acne and/or elevated androgen levels. Patients with a history of endocrinopathies, including hyperprolactinemia and thyroid diseases, and other metabolic disturbances, such as hyperlipidaemia or diabetes mellitus were excluded.

The control group included 110 healthy volunteers with no menstrual cycle irregularities, clinical or biochemical hyperandrogenism, PCO on ultrasonography, history of endocrinological or autoimmune disorders, and surgery to the pelvic region.

The cardiovascular risk was estimated in the two groups according to the criteria of the American Heart Association (AHA) and the Androgen Excess and PCOS Society (AE-PCOS), which considers the risk for type 2 diabetes mellitus, stroke, and cardiovascular disease (CVD). The following criteria were used to divide the patients in the study and control groups into at-risk [metabolically unhealthy (MU)] and not at-risk [metabolically healthy $(\mathrm{MH})]$. Patients were included in the at-risk group if any of the following factors was present: i) Obesity, particularly increased abdominal adiposity; ii) cigarette smoking; iii) hypertension; iv) dyslipidemia, increased low-density lipoprotein (LDL) cholesterol and/or non-high-density lipoprotein (HDL) cholesterol; v) impaired glucose tolerance; vi) family history of premature CVD, $<55$ and 65 years of age in male and female relatives, respectively; and vii) metabolic syndrome $(24,25)$.

Patient evaluation. Medical and family history were investigated for all patients, and clinical examination was performed, including measurement of body weight, height, waist circumference (WC) at the midpoint between the lateral iliac crest and the lowest rib margin at the end of normal expiration, waist to hip ratio (WHR), and hip circumference (HC) measured at the widest level of the greater trochanters. Body mass index (BMI) was calculated as weight in kilograms divided by the square of height in meters $\left(\mathrm{kg} / \mathrm{m}^{2}\right)$. According to the World Health Organization categories, being overweight was defined as having a BMI from $25.0-29.9 \mathrm{~kg} / \mathrm{m}^{2}$, and obesity was defined as BMI of $\geq 30.0 \mathrm{~kg} / \mathrm{m}^{2}(26)$. All the patients enrolled in the study were evaluated during the early follicular phase of the menstrual cycle (days 3-5) subsequent to discontinuation of antidiabetic and contraceptive agents for $\geq 3$ months.

Biochemical and hormonal analysis. Biochemical parameters were measured in the Central Laboratory of Poznań University of Medical Sciences (Poznań, Poland), which is a certified facility meeting the criteria of ISO 9001. Blood samples for biochemical and hormonal analysis were drawn from the antecubital vein between 8 and 10 AM following a 12-h overnight fast. Samples that were not analyzed the same day were centrifuged and the plasma was aliquoted and stored in $-70^{\circ} \mathrm{C}$ until assayed.

The 75-g oral glucose tolerance test was performed in all patients to measure glucose and insulin levels. Blood samples were obtained at baseline and at 30-min intervals for $2 \mathrm{~h}$. Glucose level in venous blood was determined by means of the enzymatic (hexokinase) method with Roche Diagnostics (Basel, Switzerland) laboratory reagents on a Roche Hitachi 912 analyzer. Insulin level was measured with the AxSYM Insulin assay (microparticle enzyme immunoassay) from Abbott Laboratories (Chicago, IL, USA).

Total serum cholesterol, HDL cholesterol, and triglycerides (TG) levels were measured with appropriate Roche Diagnostics reagents (Cholesterol CHOD-PAP, HDL-cholesterol Plus, and Triglycerides GPO-PAP, respectively) on the Roche Hitachi 912 analyzer. LDL cholesterol levels were calculated using the following formula: $\mathrm{LDL}$ cholesterol $=$ total cholesterol $-\mathrm{HDL}$ cholesterol - TG /5. The following definitions of normal levels were used: Total cholesterol, 50.0-200.0 mg/dl; HDL cholesterol, 35.0-70.0 mg/dl; triglycerides, $50.0-150.0 \mathrm{mg} / \mathrm{dl}$; and LDL cholesterol, 35.0-130.0 mg/dl.

Visceral adipose index (VAI) in females was calculated using the following formula: $\mathrm{VAI}=(\mathrm{WC} / 39.68+1.89 \times \mathrm{BMI})$ (TG /0.81) x (1.52/ HDL) (27).

Molecular analysis. The molecular analysis was performed in the Laboratory of Experimental Pharmacogenetics, Department of Clinical Pharmacy and Biopharmacy, Poznań 
University of Medical Sciences (Poznań, Poland). The ACE gene I/D polymorphism was assessed using the polymerase chain reaction (PCR) method. DNA was isolated from white blood cells with the QIAamp Blood Mini kit (Qiagen GmbH, Hilden, Germany) and PCR was performed using LightSNiP ACE 289 bp DeletionTib MolBiol GmbH (Berlin, Germany). The primers used in the PCR reaction were as follows: Forward, 5'-CTGGAGACCACTCCCATCCTTTCT-3' and reverse, 5'-GATGTGGCCATCACATTCGTCAGAT-3' for ACE gene I/D polymorphism; and an additional primer specific for the insertion, 5'-TGGGATTACAGGCGTGATACAG-3'. They were described by Rigat et al (18) and Ueda et al (28) and obtained from Tib MolBiol GmbH. The PCR reaction protocol consisted of an initial denaturation step at $95^{\circ} \mathrm{C}$ for $4 \mathrm{~min}$, followed by 30 cycles of amplification $\left(30 \mathrm{sec}\right.$ at $95^{\circ} \mathrm{C}, 30 \mathrm{sec}$ at $61^{\circ} \mathrm{C}$, and $60 \mathrm{sec}$ at $72^{\circ} \mathrm{C}$ ). The final extension step was $10 \mathrm{~min}$ at $72^{\circ} \mathrm{C}$. The PCR products were analyzed by agarose electrophoresis in the presence of ethidium bromide and visualized in UV light using a documentation system (KS 4000; Syngen Biotech Molecular Biology Instruments, Wroclaw, Poland). The following fragments were detected: Insertion/insertion (II), 480 and $160 \mathrm{bp}$; insertion/deletion (ID), 480, 190, and 160 bp; and deletion/deletion (DD), $190 \mathrm{bp}$.

Statistical analysis. All statistical analyses were performed using the Statistica version 10 PL software (StatSoft, Inc., Tulsa, OK, USA). The distribution of variables was investigated using the Shapiro-Wilk test and nonparametric tests. In particular, the Mann-Whitney U test and the Kruskal-Wallis test were used for non-normal distributions. Continuous variables are expressed as medians (interquartile range (IQR), 25-75th percentile) unless otherwise indicated. $\mathrm{P}<0.05$ was considered to indicate a statistically significant difference. Between-group differences and differences among genotype groups were assessed using the Mann-Whitney U test. $\chi^{2}$ analysis was used to compare the distribution of genotypes and alleles for the ACE polymorphism between the groups and to assess between-group differences for non-continuous variables.

The study protocol was approved by the Ethics Committee of Poznań University of Medical Sciences (Poznań, Poland). Written consent was obtained from all the subjects enrolled in the present study.

\section{Results}

The characteristics of the two groups are presented in Table I. The median average age in the control and study groups was 28.5 (26.0-31.0) and 27.0 (24.0-30.0) years, respectively $(\mathrm{P}=0.004)$. Although the subjects in the control group were significantly older than those in the study group, and it is known that older age is associated with more severe metabolic disturbances, however, no characteristics, such as high BMI and WC, elevated fasting insulin level, and presence of metabolic syndrome or dyslipidemia, were more prevalent in the controls compared with the study group subjects.

Anthropometric parameters, including BMI and WC were significantly higher in the PCOS patients. Notably, there were no differences in HC and WHR between the groups, and the present study did not observe any significant differences in blood pressure levels. Furthermore, none of the women suffered from hypertension. Although abdominal and general obesity were more frequent in the PCOS group, notably, the subjects in the control group tended to have higher levels of TG and lower HDL cholesterol concentrations. Nevertheless, the concentration of LDL cholesterol was significantly higher in the PCOS group $(\mathrm{P}<0.0001)$. Although abnormal glucose metabolism was not present in subjects from either group, a tendency in the PCOS patients to have higher fasting insulin levels was observed (Table I).

The obtained results confirmed the observation that the women in the PCOS group were significantly more predisposed to having higher WC and BMI ( $\mathrm{P}=0.000001$; Table II). No women from the control group were obese, as opposed to $26(15.45 \%)$ of the women in the study population. Although the median level of TG was lower in the PCOS group, the number of patients with abnormal TG levels was significantly higher $(\mathrm{P}=0.004)$.

ACE genotypes were subsequently analyzed. The II, ID, and DD genotype frequencies were $29.1,44.5$, and $26.4 \%$ in the controls and 5.0,37.7, and 57.3\% in the women with PCOS, respectively. In the control group, the II genotype was observed significantly more often than in the PCOS group $(\mathrm{P}<0.00001)$, whereas the DD genotype was presented significantly more often in the PCOS group $(\mathrm{P}<0.002$; Table III). The genotype distribution complied with the Hardy-Weinberg equilibrium $(\mathrm{P}>0.05)$. The frequency of the I allele was $51.4 \%$ in the control group, but only $23.9 \%$ in the study group, whereas the D allele was present in $48.6 \%$ of the controls and $76.09 \%$ of the PCOS patients $(\mathrm{P}<0.00001)$.

The association between the ACE gene I/D polymorphism and the development of metabolic disturbances was investigated. The distribution of the alleles and genotypes were associated with presence of metabolic disturbances in the groups formed according to the AHA and AE-PCOS criteria. The two groups were divided according to the presence of metabolic risk factors, and it was subsequently observed that there was a significantly higher prevalence of the D allele in all the PCOS subgroups compared with the control subgroups, irrespective of the presence of metabolic risk factors [odds ratio (OR), 3.27; $\mathrm{P}=0.0001$; Fig. 1]. There was no significant difference in the frequency of the $\mathrm{D}$ allele, which predisposes to heart disease, between the MU control subgroup (Control-MU) and the metabolically healthy control group (Control-MH; Fig. 1). By contrast, the cardioprotective I allele was encountered significantly less often in the PCOS subgroups than in the controls (OR, 3.27; $\mathrm{P}=0.0001$; Fig. 2).

The distributions of the DD and II genotypes presented in Figs. 3 and 4, respectively, confirmed that the DD genotype, which is known to increase the risk of CVD, was significantly more frequent among the PCOS patients (OR, 3.87; $\mathrm{P}=0.0003)$, whereas the cardioprotective II genotype occurred in this group less frequently $(\mathrm{OR}, 0.4 ; \mathrm{P}=0.06)$. There was no difference in the distribution of ID genotype (data not shown).

\section{Discussion}

Although the present study demonstrates the conclusion of numerous previous reports that metabolic syndrome is more frequent in women with PCOS than in the healthy 
Table I. Characteristics of the control and experimental groups.

\begin{tabular}{|c|c|c|c|}
\hline \multirow[b]{2}{*}{ Parameter } & \multicolumn{2}{|c|}{ Median (25-75) } & \multirow[b]{2}{*}{$\mathrm{P}^{\mathrm{a}}$} \\
\hline & $\begin{array}{l}\text { Control group } \\
\quad(n=110)\end{array}$ & $\begin{array}{l}\text { Study group } \\
\qquad(\mathrm{n}=138)\end{array}$ & \\
\hline Age (years) & $28.5(26.0-31.0)$ & $27.0(24.0-30.0)$ & 0.004 \\
\hline Body mass index $\left(\mathrm{kg} / \mathrm{m}^{2}\right)$ & $20.5(26.0-31.0)$ & $24.2(20.9-28.8)$ & 0 \\
\hline Hip circumference $(\mathrm{cm})$ & $87.9(92.0-101.0)$ & $97.0(92.0-108.0)$ & 0.26 \\
\hline Waist circumference $(\mathrm{cm})$ & $69.5(66.0-74.0)$ & $79.0(70.0-89.5)$ & 0 \\
\hline Waist to hip ratio & $0.72(0.7-0.76)$ & $0.78(0.75-0.80)$ & 0 \\
\hline Visceral adipose index & $2.1(1.45-3.65)$ & $2.55(2.2-2.81)$ & 0.84 \\
\hline Total cholesterol (mg/dl) & $170(156-180)$ & $188.4(164.8-212.9)$ & $<0.00001$ \\
\hline HDL cholesterol (mg/dl) & $55(45-63.5)$ & $60.2(49.7-71.2)$ & $<0.0013$ \\
\hline Tryglycerides (mg/dl) & $87(78-94)$ & $73.8(57.9-107.0)$ & 0.01 \\
\hline LDL cholesterol (mg/dl) & $78(72-88.5)$ & $106.0(88.0-124.4)$ & 0.000001 \\
\hline Fasting glucose (md/dl) & $90(84-96)$ & $88.1(83.0-93.9)$ & 0.17 \\
\hline Fasting insulin (mU/ml) & $5.4(4.6-8.02)$ & $7.6(5.2-11.5)$ & 0.000005 \\
\hline Systolic blood pressure (mm/Hg) & $110(100-120)$ & $115(100-125)$ & 0.23 \\
\hline Diastolic blood pressure $(\mathrm{mm} / \mathrm{Hg})$ & $70(60-80)$ & $70(60-80)$ & 0.34 \\
\hline
\end{tabular}

${ }^{a}$ Mann-Whitney U test. HDL, high-density lipoprotein; LDL, low-density lipoprotein.

Table II. Risk factors in the analyzed groups.

\begin{tabular}{|c|c|c|c|}
\hline Risk factor & $\begin{array}{l}\text { Control group } \\
\quad(n=110)\end{array}$ & $\begin{array}{l}\text { Study group } \\
\qquad(\mathrm{n}=138)\end{array}$ & $\mathrm{P}$ \\
\hline Cigarette smoking (n, \%) & $28(25.5 \%)$ & $48(28.57 \%)$ & $0.56^{\mathrm{a}}$ \\
\hline Family history of premature CVD (n, \%) & $0(0 \%)$ & $0(0 \%)$ & \\
\hline Metabolic syndrome (n, \%) & $0(0 \%)$ & $15(8.9 \%)$ & $0.001^{\mathrm{a}}$ \\
\hline Diabetes or fasting glucose $\geq 5.6 \mathrm{mmol} / / 1$ & $0(0 \%)$ & $0(0 \%)$ & \\
\hline High blood pressure $(\geq 130 / 85 \mathrm{mmHg})$ & $0(0 \%)$ & $0(0 \%)$ & \\
\hline High triglycerides $(\geq 1.7 \mathrm{mmol} / \mathrm{l})$ & $0(0 \%)$ & $12(7.1 \%)$ & $0.004^{\mathrm{a}}$ \\
\hline Low HDL cholesterol (<1.04 mmol/l) & $37(33.6 \%)$ & $42(25 \%)$ & $0.12^{\mathrm{a}}$ \\
\hline Increased WC (>80 cm) & $16(14.5 \%)$ & $74(44 \%)$ & $0.00001^{\mathrm{a}}$ \\
\hline Impaired fasting glucose (>5.6 mmo/l) & $12(10.9 \%)$ & $11(6,54 \%)$ & $0.19^{\mathrm{a}}$ \\
\hline Fasting insulin >5.4 (mU/ml) & $54(49.1 \%)$ & $124(73.8 \%)$ & $0.00001^{\mathrm{a}}$ \\
\hline Fasting insulin >10.4 (mU/ml) & $9(8.2 \%)$ & $59(35.1 \%)$ & $0.00001^{\mathrm{a}}$ \\
\hline Diabetes mellitus & $0(0 \%)$ & $0(0 \%)$ & \\
\hline \multicolumn{4}{|l|}{ Body mass index $\left(\mathrm{kg} / \mathrm{m}^{2}\right)$} \\
\hline Underweight $(<18.50)$ & $3(2.7 \%)$ & $5(3.0 \%)$ & $0.9^{b}$ \\
\hline Normal weight (18.50-24.99) & $94(85.4 \%)$ & $92(54.7 \%)$ & $0.0001^{\mathrm{b}}$ \\
\hline Abnormal weight (>24.99) & $13(11.8 \%)$ & $71(42.3 \%)$ & $0.00001^{\mathrm{b}}$ \\
\hline Overweight (25.00-29.99) & $13(11.8 \%)$ & $45(26.8 \%)$ & $0.003^{\mathrm{b}}$ \\
\hline Class I obesity (30.00-34.99) & $0(0 \%)$ & $15(8.9 \%)$ & $0.0013^{\mathrm{b}}$ \\
\hline Class II obesity (35.00-39.99) & $0(0 \%)$ & $10(5.95 \%)$ & $0.009^{\mathrm{b}}$ \\
\hline Class III obesity ( $\geq 40.00$ ) & $0(0 \%)$ & $1(0.6 \%)$ & $0.4^{\mathrm{b}}$ \\
\hline
\end{tabular}

${ }^{a}$ Mann-Whitney U test, ${ }^{b} \chi^{2}$ test. CVD, cardiovascular disease; HDL, high-density lipoprotein; WC, waist circumference.

population $(29,30)$, the prevalence of metabolic syndrome in the study population (8.9\%) is low compared to the results of Apridonidze et al (29) and the data obtained in women who participated in the National Health and Nutrition Examination Survey III survey (30). In fact, this frequency is only slightly higher than the estimated overall frequency of $6 \%$ in women 
Table III. Distributions of ACE-1 genotypes and I and D alleles in the study and control groups.

\begin{tabular}{lccc}
\hline ACE-1 & $\begin{array}{c}\text { Control group } \\
(\mathrm{n}=110)\end{array}$ & $\begin{array}{c}\text { Study group } \\
(\mathrm{n}=138)\end{array}$ & \\
\hline Genotype & & $7(5.07 \%)$ & $<0.00001$ \\
II & $32(29.1 \%)$ & $52(37.68 \%)$ & 0.274 \\
ID & $49(44.5 \%)$ & $79(57.25 \%)$ & $<0.002$ \\
DD & $29(26.4 \%)$ & $66(23.91 \%)$ & $<0.00001$ \\
Allele & & $210(76.09 \%)$ & $<0.00001$ \\
I & $113(51.4 \%)$ & & \\
D & $107(48.6 \%)$ & & \\
\hline
\end{tabular}

${ }^{a} \chi^{2}$ test. ACE-1, angiotensin converting enzyme-1.

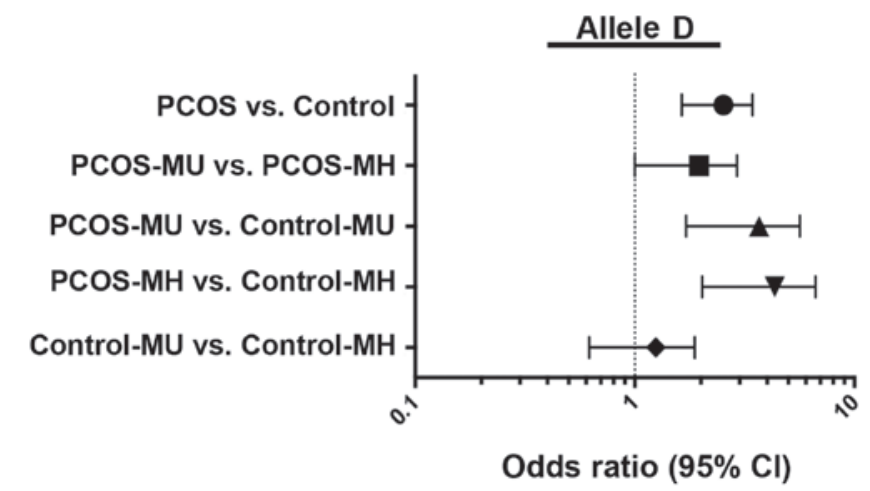

Figure 1. Association between the presence of metabolic disturbances in women with PCOS and the presence of allele D of the angiotensin converting enzyme gene insertion/deletion polymorphism. OR, 3.27; $\mathrm{P}=0.0001$. PCOS, polycystic ovary syndrome; $\mathrm{MH}$, metabolically healthy; MU, metabolically unhealthy; CI, confidence interval.

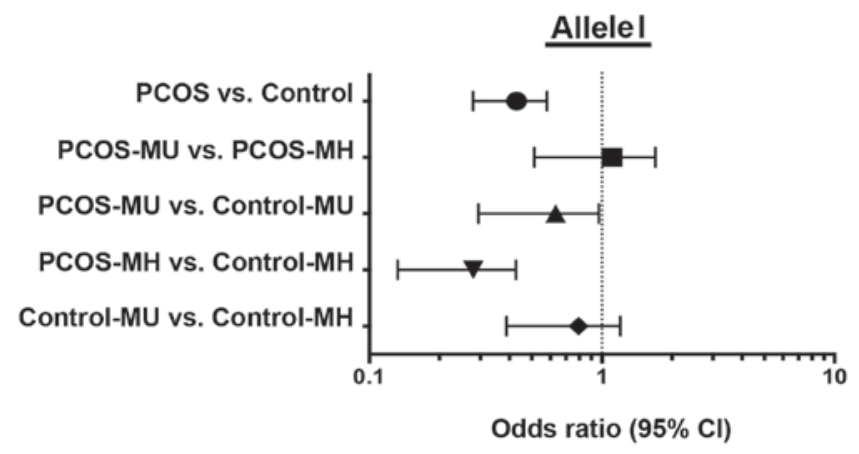

Figure 2. Association between the presence of metabolic disturbances in women with PCOS and the presence of allele I of the angiotensin converting enzyme gene insertion/deletion polymorphism. OR, 3.27; $\mathrm{P}=0.0001$. PCOS, polycystic ovary syndrome; $\mathrm{MH}$, metabolically healthy; $\mathrm{MU}$, metabolically unhealthy; CI, confidence interval.

between 20 and 29 years old (30). As presented in Tables I and II, the predominant indicators of metabolic syndrome in PCOS women are increased BMI and deranged biochemical profile. Despite the presence of numerous women with obesity, there were no subjects with hypertension in either of the groups, and no tendency to exhibit higher blood pressure was detected, which may be associated with the young age of the

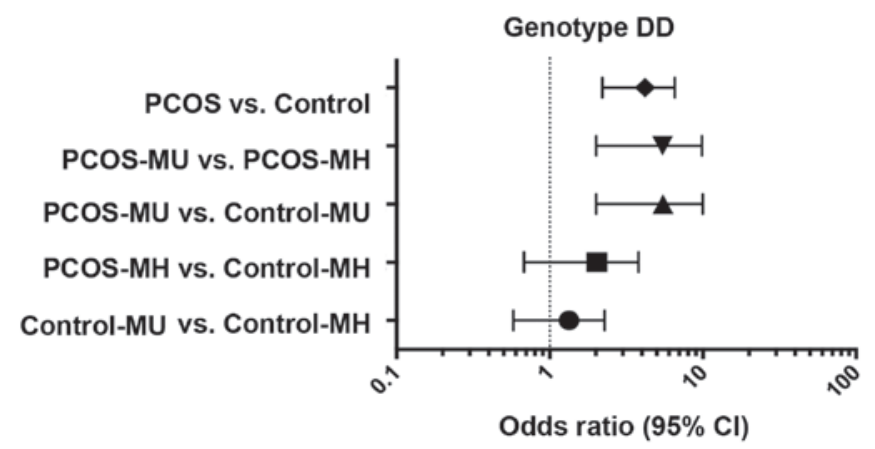

Figure 3. Association between the presence of metabolic disturbances in women with PCOS and the presence of genotype DD of the angiotensin converting enzyme gene insertion/deletion polymorphism. OR, 3.87; $\mathrm{P}=0.0003$ PCOS, polycystic ovary syndrome; $\mathrm{MH}$, metabolically healthy; MU, metabolically unhealthy; CI, confidence interval.

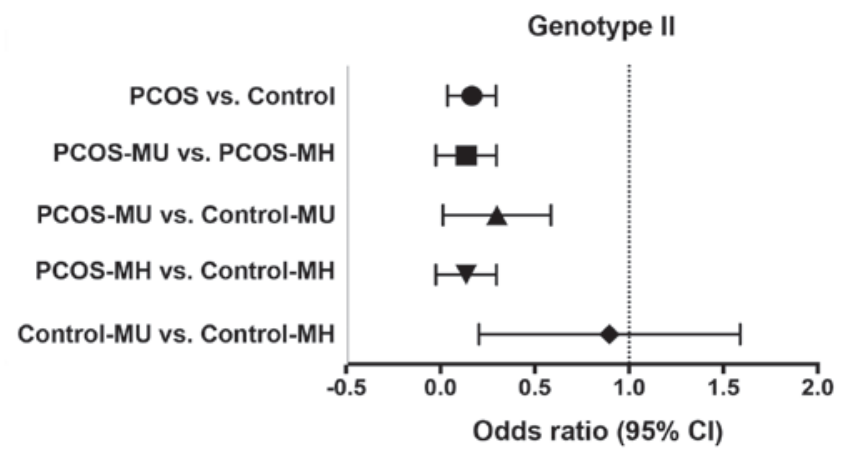

Figure 4. Association between the presence of metabolic disturbances in women with PCOS and the presence of genotype II of the angiotensin converting enzyme gene insertion/deletion polymorphism. OR, $0.4 ; \mathrm{P}=0.06$. PCOS, polycystic ovary syndrome; $\mathrm{MH}$, metabolically healthy; MU, metabolically unhealthy; CI, confidence interval.

participants. These results contradict the previous findings of Chen et al (31) who indicated that PCOS and accompanying hyperandrogenemia in young women with PCOS were associated with elevated systolic and diastolic blood pressure independently of age and presence of insulin resistance, obesity, and dyslipidemia. Notably, the PCOS patients in the present study had healthier lipid profiles compared with the controls. The higher levels of HDL cholesterol and 
the lower levels of TG in the study group suggest that there may be a different mechanism underlying the development of metabolic disturbances in women with PCOS compared with healthy women. This finding is in disagreement with the results of Legro et al (32) who observed that PCOS patients more frequently exhibited low HDL cholesterol levels and hypertriglyceridemia. Cardoso et al (33), who investigated the association between the ACE gene D/I polymorphism and lipid profile, demonstrated that, in the general population, women with the DD genotype had the highest mean values of triglyceride levels, while women with the II genotype had the highest mean values of HDL cholesterol (33). The subjects in the PCOS group in the present study had higher concentrations of HDL cholesterol and lower TG levels, and the majority of them had the DD genotype. Low serum HDL cholesterol is a known risk factor of CVD, independently of serum LDL cholesterol levels (34). Therefore, the finding of the present study and the results of Apridonidze et al (29) who also suggested that the presence of PCOS by itself confers an increased risk of metabolic syndrome, indicate that this disturbance may have an alternative pathogenesis.

The role of ACE in RAS is crucial as it is responsible for the regulation of blood pressure, angiogenesis of ovarian endothelium, growth of follicles, steroidogenesis, and inflammation. ACE is expressed in multiple tissues, including the ovaries, and contributes to the genesis of numerous disorders (6,7). More than 76 polymorphisms in the ACE gene have been identified, with the ACE I/D polymorphism being the most common. The frequency of this polymorphism in women with PCOS requires further elucidation, and the association between the ACE I/D polymorphism and PCOS and its complications has not yet been confirmed.

The present study has demonstrated that women with PCOS exhibit a significantly higher prevalence of the D allele, which predisposes them to CVD and hypertension, and they are less likely to have the protective I allele. This finding contradicts the previous results of Sun et al (19) who did not observe differences in genotypic distribution between patients with PCOS and controls. Numerous possibilities may account for this discrepancy. First, the previous study predominantly aimed to investigate whether ACE-1 polymorphism has an impact on the pathogenesis of PCOS, rather than on the development of metabolic disturbances. The smaller sample size in the present study may be another factor. In this regard, the study of Deepika et al (35) which was performed in a large group of patients, confirmed the results of the present study that the DD genotype occurs significantly more often and the II genotype less often in PCOS patients compared with healthy controls. However, in this previous study the frequencies of the D and I alleles did not vary significantly between the groups.

Notably, although the control group was older, and age is a risk factor in metabolic disorders, metabolic syndrome was more frequently observed in the PCOS group. Deepika et al (35) suggested that the DD genotype in women with PCOS may be a risk factor for the early onset of symptoms, including hyperandrogenism, insulin resistance, obesity, and enhanced RAS activity. This may confirm the findings of the present study that indicate metabolic risk factors were present more frequently in the PCOS group and in the subgroups with the II genotype.
Finally, the finding that MU subjects had significantly higher fasting insulin levels is in line with the results of a previous study that demonstrated an association between the presence of acanthosis, a marker for insulin resistance, in women with $\mathrm{D}$ alleles and DD genotypes (35). The present study determined that there is an association between the ACE I/D polymorphism and the presence and intensity of metabolic disturbances in PCOS women. Future studies should aim detect patients at higher risk of developing metabolic complications in order to alter their lifestyle and diet. Metabolic improvement during the early years of genetically at-risk individuals may attenuate the risk and progression of CVD.

\section{Acknowledgements}

The authors would like to thank Editage (www.editage.com) for their English language editing. The present study was funded by the Grant for Young Scientists by the Poznań University of Medical Sciences (Poznań, Poland)

\section{References}

1. Yoshimura Y: The ovarian renin-angiotensin system in reproductive physiology. Front Neuroendocrinol 18: 247-291, 1997.

2. Van Sande ME, Scharpé SL, Neels HM and Van Camp KO: Distribution of angiotensin converting enzyme in human tissues. Clin Chim Acta 147: 255-260, 1985.

3. Soubrier F, Wei L, Hubert C, Clauser E, Alhenc-Gelas F and Corvol P: Molecular biology of the angiotensin I converting enzyme: II. Structure-function. Gene polymorphism and clinical implications. J Hypertens 11: 599-604, 1993.

4. Palumbo A, Pourmotabbed G, Carcangiu ML Andrade-Gordon P, Roa L, DeCherney A and Naftolin F: Immunohistochemical localization of renin and angiotensin in the ovary: Comparison between normal women and patients with histologically proven polycystic ovarian disease. Fertil Steril 60: 280-284, 1993.

5. Johnson MC, Vega M, Vantman D, Troncoso JL and Devoto L: Regulatory role of angiotensin II on progesterone production by cultured human granulosa cells. Expression of angiotensin II type-2 receptor. Mol Hum Reprod 3: 663-668, 1997.

6. Plendl J, Neumüller C, Vollmar A, Auerbach R and Sinowatz F: Isolation and characterization of endothelial cells from different organs of fetal pigs. Anat Embryol (Berl) 194: 445-456, 1996.

7. Acosta TJ, Berisha B, Ozawa T, Sato K, Schams D and Miyamoto A: Evidence for a local endothelin-angiotensin-atrial natriuretic peptide systemin bovine mature follicles in vitro: Effects on steroid hormones and prostaglandin secretion. Biol Reprod 61: 1419-1425, 1999.

8. Stefanello JR, Barreta MH, Porciuncula PM, Arruda JN, Oliveira JF, Oliveira MA and Gonçalves PB: Effect of angiotensin II with follicle cells and insulin-like growth factor-I or insulin on bovine oocyte maturation and embryo development. Theriogenology 66: 2068-2076, 2006.

9. Nielsen AH, Hagemann A, Svenstrup B, Nielsen J and Poulsen K: Angiotensin II receptor density in bovine ovarian follicles relates to tissue renin and follicular size. Clin Exp Pharmacol Physiol 21: 463-469, 1994.

10. Azziz R, Carmina E, Dewailly D, Diamanti-Kandarakis E, Escobar-Morreale HF, Futterweit W, Janssen OE, Legro RS, Norman RJ, Taylor AE, et al: The androgen excess and PCOS society criteria for the polycystic ovary syndrome: The complete task force report. Fertil Steril 91: 456-488, 2009.

11. Diamanti-Kandarakis E: Polycystic ovarian syndrome: Pathophysiology, molecular aspects and clinical implications. Expert Rev Mol Med 10: e3, 2008.

12. Cho LW, Randeva HS and Atkin SL: Cardiometabolic aspects of polycystic ovarian syndrome. Vasc Health Risk Manag 3: 55-63, 2007.

13. Diamanti-Kandarakis E, Piperi C, Spina J, Argyrakopoulou G, Papanastasiou L, Bergiele A and Panidis D: Polycystic ovary syndrome: The influence of environmental and genetic factors. Hormones (Athens) 5: 17-34, 2006. 
14. Pérez MS, Cerrone GE, Benencia H, Márquez N, De Piano E and Frechtel GD: Polymorphism in CYP11alpha and CYP17 genes and the etiology of hyperandrogenism in patients with polycystic ovary syndrome. Medicina (B Aires) 68: 129-134, 2008 (In Spanish).

15. Mlinar B, Pfeifer M, Vrtacnik-Bokal E, Jensterle M and Marc J: Decreased lipin 1 beta expression in visceral adipose tissue is associated with insulin resistance in polycystic ovary syndrome. Eur J Endocrinol 159: 833-839, 2008.

16. Christopoulos P, Mastorakos G, Gazouli M, Panidis D, Deligeoroglou E, Katsikis I, Papadias K, Diamandi-Kandarakis E and Creatsas G: Genetic variants in TCF7L2 and KCNJ11 genes in a Greek population with polycystic ovary syndrome. Gynecol Endocrinol 24: 486-490, 2008.

17. Giacchetti G, Sechi LA, Rilli S and Carey RM: The renin-angiotensin-aldosterone system, glucose metabolism and diabetes. Trends Endocrinol Metab 16: 120-126, 2005.

18. Rigat B, Hubert C, Alhenc-Gelas F, Cambien F, Corvol P and Soubrier F: An insertion/deletion polymorphism in the angiotensin I-converting enzyme gene accounting for half the variance of serum enzyme levels. J Clin Invest 86: 1343-1346, 1990.

19. Sun J, Fan H, Che Y, Cao Y, Wu X, Sun HX, Liang F, Yi L and Wang Y: Association between ACE gene I/D polymorphisms and hyperandrogenism in women with polycystic ovary syndrome (PCOS) and controls. BMC Med Genet 10: 64, 2009.

20. Celik O, Yesilada E, Hascalik S, Celik N, Sahin I, Keskin L and Ozerol E: Angiotensin-converting enzyme gene polymorphism and risk of insulin resistance in PCOS. Reprod Biomed Online 20: 492-498, 2010.

21. Karabulut A, Turgut S and Turgut G: Angiotensin converting enzyme gene insertion/deletion polymorphism in patients with polycystic ovary syndrome. Gynecol Endocrinol 26: 393-398, 2010.

22. Amsterdam ESHRE/ASRM-Sponsored 3rd PCOS Consensus Workshop Group: Consensus on women's health aspects of polycystic ovary syndrome (PCOS). Hum Reprod 27: 14-24, 2012.

23. Ferriman D and Gallwey JD: Clinical Assessment of body hair growth in women. J Clin Endocrinol Metab 21: 1440-1447, 1961.

24. Amato MC, Guarnotta V, Forti D, Donatelli M, Dolcimascolo S and Giordano C: Metabolically healthy polycystic ovary syndrome (MH-PCOS) and metabolically unhealthy polycystic ovary syndrome (MU-PCOS): A comparative analysis of four simple methods useful for metabolic assessment. Hum Reprod 28: 1919-1928, 2013.
25. Grundy SM, Cleeman JI, Daniels SR, Donato KA, Eckel RH, Franklin BA, Gordon DJ, Krauss RM, Savage PJ, Smith SC Jr, et al: Diagnosis and management of the metabolic syndrome: An American heart association/national heart, lung and blood institute scientific statement. Circulation 112: 2735-2752, 2005.

26. Obesity: Preventing and managing the global epidemic. Report of a WHO consultation. World Health Organ Tech Rep Ser 894 i-xii.1-253, 2000.

27. Amato MC, Giordano C, Galia M, Criscimanna A, Vitabile S, Midiri M and Galluzzo A; AlkaMeSy Study Group: Visceral adiposity index: A reliable indicator of visceral fat function associated with cardiometabolic risk. Diabetes Care 33: 920-922, 2010.

28. Ueda S, Heeley RP, Lees KR, Elliott HL and Connell JM: Mistyping of the human angiotensin-converting enzyme gene polymorphism: Frequency, causes and possible methods to avoid errors in typing. J Mol Endocrinol 17: 27-30, 1996.

29. Apridonidze T, Essah PA, Iuorno MJ and Nestler JE: Prevalence and characteristics of the metabolic syndrome in women with polycystic ovary syndrome. J Clin Endocrinol Metab 90: 1929-1935, 2005

30. Ford ES, Giles WH and Dietz WH: Prevalence of the metabolic syndrome among US adults: Findings from the third national health and nutrition examination survey. JAMA 287: 356-359, 2002.

31. Chen MJ, Yang WS, Yang JH, Chen CL, Ho HN and Yang YS: Relationship between androgen levels and blood pressure in young women with polycystic ovary syndrome. Hypertension 49: 1442-1447, 2007.

32. Legro RS, Urbanek M, Kunselman AR, Leiby BE and Dunaif A: Self-selected women with polycystic ovary syndrome are reproductively and metabolically abnormal and undertreated. Fertil Steril 78: 51-57, 2002.

33. Cardoso RL, Nogueira AR, Salis LH, Urményi TP, Silva R, Moura-Neto RS, Pereira BB, Rondinelli E and Souza e Silva NA: The association of ACE gene D/I polymorphism with cardiovascular risk factors in a population from Rio de Janeiro. Braz J Med Biol Res 41: 512-518, 2008.

34. Feig JE, Hewing B, Smith JD, Hazen SL and Fisher EA: High-density lipoprotein and atherosclerosis regression: Evidence from preclinical and clinical studies. Circ Res 114 205-213, 2014.

35. Deepika ML, Reddy KR, Rani VU, Balakrishna N, Latha KP and Jahan P: Do ACE I/D gene polymorphism serve as a predictive marker for age at onset in PCOS? J Assist Reprod Genet 30: $125-130,2013$. 